Original Research Article

\title{
Drug utilization study of some antibiotic in indoor setting at tertiary care teaching hospital in Central India: a descriptive study
}

\author{
Rahul D. Randad*, Sudharam T. Bhagwate, Mohd. Khalid Inamdar
}

Department of Pharmacology, Government Medical College, Akola, Maharashtra, India

Received: 15 February 2017

Accepted: 28 March 2017

*Correspondence to:

Dr Rahul D. Randad,

Email: rrahul.m04@gmail.com

Copyright: (C) the author(s), publisher and licensee Medip Academy. This is an openaccess article distributed under the terms of the Creative Commons Attribution NonCommercial License, which permits unrestricted noncommercial use, distribution, and reproduction in any medium, provided the original work is properly cited

\begin{abstract}
Background: Antibiotics are one of the most important discoveries in the field of medicine and are widely used in reducing the infections. Irrational antibiotic use may result in increased cost of treatment, drug-drug interactions also cause severe adverse reactions. The objective of the study was to determine average number of antibiotics prescribed per prescription, to identify the indication for which antibiotics were commonly used and to determine the most commonly prescribed antibiotics in a tertiary care hospital.

Methods: This was a retrospective observational study. About 300 patients who were prescribed antibiotics were included in the study. The data on antibiotic containing prescriptions from each patient was collected from the inpatient of medicine department. The study was carried out from August 2013 to July 2014.

Results: Total 300 prescriptions studied, of which 195 (65\%) prescriptions had 2 antibiotics per prescriptions and $105(35 \%)$ prescriptions had more than 2 antibiotics per prescription. It was observed that out of 300 patients, 165 were male $(55 \%)$ and 135 were female $(45 \%)$. Fluoroquinolones were most commonly prescribed antibiotics and ciprofloxacin was prescribed mostly. Most of the prescriptions contained polypharmacy. The antibiotics treatment regimens given in most of the patients were without done culture sensitivity test before prescribing, which lead to irrational prescribing.

Conclusions: Compliance to adopted treatment guidelines is still a major challenge hence there is an urgent need for following antimicrobial policy.
\end{abstract}

Keywords: Antibiotic, Polypharmacy, Prescription pattern, Rational prescribing

\section{INTRODUCTION}

Antibiotics are among the most common medications prescribed both in the hospital setting and the community setting. ${ }^{1}$ As the consumption of antibiotic rises, resistance to antibiotics becomes a major threat to public health. Existing evidence suggests that there is a causal association between antimicrobial usage in hospital and antimicrobial resistance. $^{2}$

Antimicrobial resistance, a global problem, is particularly pressing in developing countries where the infectious disease burden is high and cost constrains the replacement of older antibiotics with newer, more expensive ones. ${ }^{3}$ It can be caused by various factors such as health facilities, medication non adherence, multiple prescribers and dispensers, use of first generation medications, inappropriate usage of medication, intake of wrong dosage, incorrect usage of medications, use of counterfeit drugs, over and under usage of medications, animal husbandry, etc. ${ }^{4}$

The study of prescription pattern is generally a part of a medical audit that looks for appraisal, and, if required, modification, in prescription pattern, to obtain rational and cost-effective medical care. ${ }^{5}$ There is evidence that antibiotic usage in hospitals is increasing, and that over a third of prescriptions are not compliant with evidencebased guidelines. In Denmark, antibiotic usage in hospitals increased by $18 \%$ between 1997 and 2001. A similar study carried out in the Netherlands revealed that hospital antibiotic usage between 1997 and 2000 
increased by $10.6 \% .^{6}$ Appropriate antibiotic use is of both clinical and economic significance to any health system and should be given adequate attention. ${ }^{7}$

Keeping these facts in mind, this study is planned with the objective of determining the average number of antibiotics prescribed per prescription, identifying the indication for which the antibiotics were commonly used and determining the most commonly prescribed antibiotics at tertiary care teaching hospital in Central India.

\section{METHODS}

This study was a non-interventional, retrospective, observational study, conducted at Government Medical College and Hospital (GMCH), Akola, Maharashtra. After clearance from the institutional ethics committee and with the permission from Officer of Medical Record Department case files satisfying, the inclusion and exclusion criteria were considered for the study. A total of 300 prescriptions were collected and analysed in the Department of Pharmacology at GMCH, Akola.

Indoor cases of adult patients (age $\geq 18-65$ years) admitted in medicine ward between August 2013 and July 2014 were collected from medical record section of GMCH, Akola. The study was carried out for antibiotic, which is commonly prescribed at a Government Medical college and Hospital, Akola. Almost every prescription had antibiotic in case of indoor patients, so some antibiotics were considered for study purpose not all.

All the prescriptions had complete documentation of information including, patients demographic characteristics, date of admission and discharge, clinical diagnosis, drug name, dose and route of administration, investigations, rationality and outcome of health status.

\section{RESULTS}

A total of 300 prescriptions were analysed. Out of 300 patients $165(55 \%)$ were male and 135 (45\%) were female. Mean age of the patients in study is $34.42 \pm 11.54$ (Mean \pm SD) years of which mean age of male cases where $33 \pm 17.95$ years and of females where $27 \pm 20.54$ years.

Table 1: Age wise distribution of cases.

\begin{tabular}{|lll|}
\hline Age (years) & No. of cases & $\%$ \\
\hline$\leq 18-20$ & 23 & 7.67 \\
\hline $21-30$ & 110 & 36.67 \\
\hline $31-40$ & 90 & 30.00 \\
\hline $41-50$ & 41 & 13.67 \\
\hline$\geq 51$ & 36 & 12.00 \\
\hline Total & 300 & 100 \\
\hline Mean \pm SD* & $34.42 \pm 11.54$ & \\
\hline
\end{tabular}

*SD - Standard deviation
The age group 21-30 years accounted for highest number $110(36.67 \%)$ of patients. Least number of cases where found to be $23(7.67 \%)$ in age group $\leq 18$-20 years (Table 1).

Out of 300 prescriptions, Acute Gastroenteritis was the most common illness found in $55(18.33 \%)$ cases during study period followed by Malaria found in $52(17.33 \%)$ cases which is followed by PUO and Typhoid fever in 45 (15\%) cases (Figure 1).

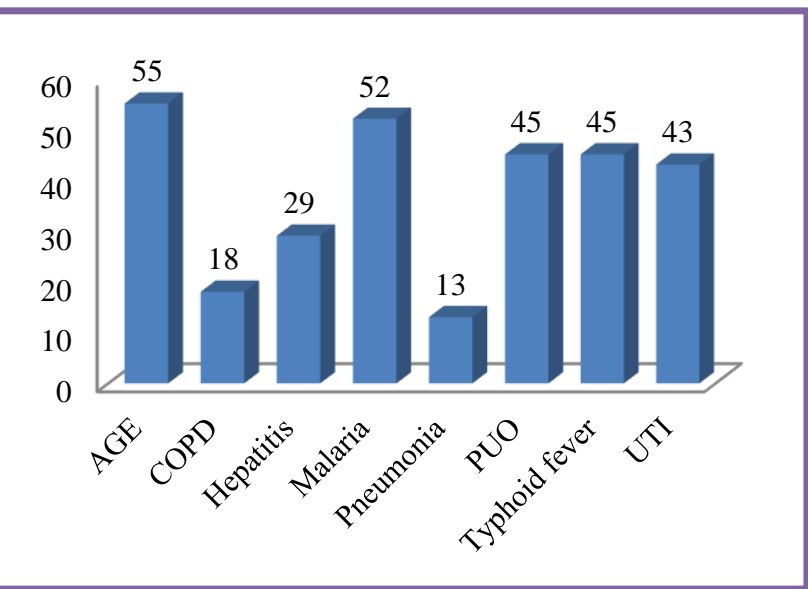

AGE: Acute gastroenteritis, COPD: Chronic obstructive pulmonary disease, PUO: Pyrexia of unknown origin, UTI: Urinary tract infection.

Figure 1: Illness wise distribution of cases.

Amongst prescribed antibiotics, it is observed from Table 2 that ciprofloxacin is most commonly prescribed antibiotic seen in $261(87 \%)$ number of prescriptions followed by metronidazole seen in 146 (48.67\%) prescriptions which is followed by ceftriaxone and cefotaxime in $85(28.33 \%)$ prescriptions each. Antibiotic least commonly prescribed in present study was cefoperazone-sulbactum combination and amoxycilinclavulanic acid combination in 14 (4.67\%) and 9 (3\%) number of prescriptions respectively.

\section{Table 2: Commonly prescribed antibiotics.}

\begin{tabular}{|lll|}
\hline Drug & No. of cases & $\%$ \\
\hline Amox-clav & 9 & 3 \\
\hline Artesunate & 52 & 17.33 \\
\hline Cefopera+sulb & 14 & 4.67 \\
\hline Cefotaxime & 85 & 28.33 \\
\hline Ceftriaxone & 85 & 28.33 \\
\hline Ciprofloxacin & 261 & 87 \\
\hline Metronidazole & 146 & 48.67 \\
\hline Norfloxacin & 39 & 13 \\
\hline
\end{tabular}

In present study, almost all antibiotic prescribed are included in National List of Essential Medicines (2011), India and in WHO Model List of Essential Medicines (17th edition, March 2011) except Norfloxacin and Cefoperazone+Sulbactum combination. 
Table 3: Extent of polypharmacy and other parameters.

\begin{tabular}{|ll|}
\hline Parameter & Number \\
\hline $\begin{array}{l}\text { Average number of antibiotic per } \\
\text { prescription }\end{array}$ & 3.5 \\
\hline$\%$ of prescription having 2 antibiotic & 65 \\
\hline$\%$ of prescription having 3 antibiotic & 32 \\
\hline$\%$ of prescription having 4 antibiotic & 3 \\
\hline$\%$ of C/S report done & 2 \\
\hline $\begin{array}{l}\text { \% of prescription having appropriate } \\
\text { outcome }\end{array}$ & 70.33 \\
\hline $\begin{array}{l}\% \text { of empiric criteria for initial antibiotic } \\
\text { selection }\end{array}$ & 98 \\
\hline
\end{tabular}

\section{DISCUSSION}

It was found that antibiotic prescribing patterns at GMCH, Akola were irrational. Around $50 \%$ of these prescriptions of antibiotics are not needed, are inappropriate or are in wrong doses. The fear of physician whether he is missing any occult infection also makes him to use antibiotic umbrella for protecting him and his patient. ${ }^{8}$ In order to get breakthrough from the irrational pattern of prescribing behaviour of antibiotic this study is done.

Out of 300 cases studied, number of cases having Male patients was $165(55 \%)$ and Females cases were 135 (45\%). This result closely corresponds to results obtained in Ashish Pathak et al. study which shows 58\% male cases and $42 \%$ females cases. ${ }^{4,9}$ The reason for more number of male cases would be that males were exposed to external environment more as compared to females. Most common illness found in present study was GIT infection. As present study has one-year duration, so, incidence of particular illness depends on various factors such as, seasonal variations, epidemics during study, age and sex of patients etc. Most commonly prescribed antibiotic was Ciprofloxacin followed by Metronidazole and subsequently Cefotaxime and Ceftriaxone. Most of the studies shows results similar to present study. ${ }^{4,8,10-13}$

Only $6(2 \%)$ number of cases had Culture and Sensitivity test done. These suggest that in most of the prescriptions criteria for initial selection of antibiotic was Empirical. Akram Ahmad et al (2014) study had similar observation that culture and sensitivity test was not done in most of the patients before prescribing antibiotics. ${ }^{4}$ Empiric use of antibiotic is one of the factor for growing rate of Antimicrobial resistance. It is widely accepted that there is a direct correlation between the use of antibiotics and development of antibiotic resistance. ${ }^{14-16}$ Use of culture specific antimicrobials should also be promoted to reduce chances of drug resistance. ${ }^{17}$

Average number of drugs per prescription is an important indicator of prescription audit. It is preferable to keep the mean number of drugs per prescription as minimum as possible. This will help to avoid the drug-drug interactions, development of bacterial resistance and increase hospital cost. ${ }^{18}$ Average number of antibiotic per prescription in present study was found to be 3.5. This is higher than those reported by Sharma D et al which was only $1 .{ }^{19}$ But result of present study was in approximate correspond to observation by Bharti Mahajan et al which had 3.36 AMA per prescription. ${ }^{20} 3.02$ is the average number of AMA per prescription in study of Deshmukh VS et al. ${ }^{8}$

Most of the prescriptions had injectable antibiotic preferably as cases were from indoor setting. Majority of antibiotic were prescribed from National List of Essential Medicine, India and in WHO Model List of Essential Medicines (17 $7^{\text {th }}$ edition).

\section{Limitations}

Limitations of the study were its sample size, as more be the size of sample population more significant will be the results. Adverse drug reactions were not noted due to lack of ADR reporting by treating physicians, interns, or medical officers on duty. WHO indicator of prescription like number of generic drug prescribed was not considered as study parameter because most of the antibiotics were prescribed by brand names. Use of generic drugs has declined over the years and this issue must be dealt seriously.

\section{CONCLUSION}

From the study findings, it could be concluded that prescribing pattern followed in tertiary care hospital is not in accordance with National Treatment Guidelines for Antimicrobial Use in infectious diseases. The overuse of antibiotics has resulted in the emergence of drug-resistant strain, which is very difficult to treat. Emergence of antibiotic resistant strains cause considerable impact on patient treatment and outcomes adding to the increased length of stay in the hospital, additional co-morbid conditions and increased treatment cost. Compliance to adopted treatment guidelines is still a major challenge hence there is an urgent need for following antimicrobial policy.

Funding: No funding sources

Conflict of interest: None declared

Ethical approval: The study was approved by the Institutional Ethics Committee

\section{REFERENCES}

1. Gururaja MP, Sarah A, Samaga L, Joshi H, Nair S, Shastry CS. Cephalosporin utilization evaluation in a university teaching hospital: a prospective study. J Drug Deliv Therapeu. 2013;3(2):83-7.

2. Abhijit K, Jain P, Upadhyaya P, Jain S. Antibiotic prescribing in various clinical departments in a 
tertiary care teaching hospital in Northern India. J Clin Diagn Res. 2014;8(5):09-11.

3. GARP-India Working Group. Rationalizing antibiotic use to limit antibiotic resistance in India. Indian $\mathbf{J}$ Med Res. 2011;134:281-94.

4. Ahmad A, Revanker M, Haque I, Pravina A, Ivan R, Dasari R et al. Study the prescription pattern of antibiotics in the medicine department in a teaching hospital: a descriptive study. Int J Toxicol Pharmacol Res. 2014;6(2):43-6.

5. Marr JJ, Moffet HL, Kunin CM. Guidelines for improving the use of antimicrobial agents in hospitals: A statement by the Infectious Diseases Society of America. J Infect Dis. 1988;157:869-76.

6. Davey P, Brown E, Charani E, Fenelon L, Gould IM, Holmes $\mathrm{A}$ et al. Interventions to improve antibiotic prescribing practices for hospital inpatients (Review). Cochrane Database Syst Rev. 2013 Apr 30;(4):CD003543.

7. Rachana PR, Anuradha HV, Shivamurthy MC. Anti hypertensive prescribing patterns and cost analysis for primary hypertension: A retrospective study. J Clin Diagn Res. 2014;8(9):19-22.

8. Deshmukh VS, Khadke VV, Patil AW, Lohar PS. Study of prescribing pattern of antimicrobial agents in indoor patients of a tertiary care hospital. Int $\mathrm{J}$ Basic Clin Pharmacol. 2013;2:281-5.

9. Pathak A, Mahadik K, Dhaneria SP, Sharma A, Eriksson B, Lundborg CS. Surveillance of Antibiotic Consumption Using the Focus of Infection Approach in 2 Hospitals in Ujjain, India. PLoS ONE. 2012;7(6):1-9.

10. Badar VA, Navale SB. Study of prescribing pattern of antimicrobial agents in medicine intensive care unit of a teaching hospital in Central India. JAPI, 2012;60:20-3.

11. Ahmed MM, EL Maraghy AA, Andrawas EW. Study of prescription patterns of antibiotics in treating lower respiratory tract infections at Sohag Chest
Hospital. Egyptian J Chest Diseas Tuberculosis. 2016;65:143-55.

12. Ramesh KT, Shahina S, Shobha JC, Naidu MUR, Rani PU, Vijay T. Drug utilization in geriatric population in a tertiary care centre. J Med Edu Res. 1999;1(3):118-20.

13. Shankar PR, Upadhyay DK, Mishra P, Subish P, Dubey AK, Sahaet AC. Fluoroquinolone utilization among inpatients in a teaching hospital in Western Nepal. J Pak Med Assoc. 2007;57(2):78-82.

14. Charani E, Cooke J, Holmes, A. Antibiotic stewardship programmes-what's missing? J Antimicrob Chemother. 2010;65:2275-7.

15. Livermore DM. The zeitgeist of resistance. J Antimicrob Chemother. 2007;60(1):59-61.

16. Livermore DM. Minimising antibiotic resistance. Lancet Infect Dis. 2005;5:450-9.

17. Jhaveri BN, Patel TK, Barvaliya MJ, Tripathi CB. Drug utilization pattern and pharmacoeconomic analysis in geriatric medical in-patients of a tertiary care hospital of India. J Pharmacol Pharmacother. 2014;5:15-20.

18. Atanasova I, Terziivanov D. Investigation on antibiotics in a hospital for a one-year period. Int $\mathbf{J}$ Clin Pharmacol Ther. 1995;33:32-3.

19. Sharma D, Reeta K, Badyal DK, Garg SK, Bhargava VK. Antimicrobial prescribing pattern in an Indian tertiary hospital. Indian $\mathbf{J}$ Physiol Pharmacol. 1998;42:533-7.

20. Mahajan B, Kaushal S, Chopra SC. A Drug Utilization Study of Antimicrobial agents (AMAs) in the Intensive Care Units (ICUs) at Medical College Hospital of North India. JK Sci. 2013;15(3):129-32.

Cite this article as: Randad RD, Bhagwate ST, Inamdar MK. Drug utilization study of some antibiotic in indoor setting at tertiary care teaching hospital in Central India: a descriptive study. Int J Basic Clin Pharmacol 2017;6:1123-6. 